\title{
ALÉM DOS HUMANOS: REFLEXÕES SOBRE O PROCESSO DE INCORPORACÃOO DOS DIREITOS AMBIENTAIS COMO DIREITOS HUMANOS NAS CONFERÊNCIAS DAS NACOÕES UNIDAS
}

\author{
Carlos Alberto Steil \\ Rodrigo Toniol ${ }^{*}$ \\ Universidade Federal do Rio Grande do Sul - Brasil
}

Resumo: Desde 1972 a Organização das Nações Unidas (ONU) promove reuniões globais para discutir questões relacionadas ao meio ambiente. A permanência desta temática na agenda política da ONU, contudo, não significa que o que seja meio ambiente, natureza e ecologia tenha permanecido inabalável desde então. Neste artigo refletimos sobre a produção da ideia de direitos ambientais enquanto direitos humanos a partir da análise de materiais resultantes de algumas das conferências das Nações Unidas sobre meio ambiente e também das conferências nacionais sobre direitos humanos. A partir da análise do princípio de "defesa da vida", da ideia de justiça ambiental e, por fim, do surgimento de alguns mecanismos burocráticos de denúncia de crimes ambientais, apresentamos algumas das principais articulações entre direitos humanos e direitos ambientais no Brasil.

Palavras-chave: direitos ambientais, direitos humanos, Organização das Nações Unidas, reuniões globais.

Abstract: Since 1972 the United Nations (UN) promotes global meetings to discuss issues related to the environment. The permanence of this issue on the political agenda of the UN, however, does not mean that the notions of the environment, nature and ecology have remained the same. In this article we reflect on the production of the idea of environmental rights as human rights. We analyse materials from some of the United Nations Conferences on the Environment and also of national conferences on human rights. After discussing the principle of "defense of life", the idea of

* Doutorando em Antropologia Social.

Horizontes Antropológicos, Porto Alegre, ano 19, n. 40, p. 283-309, jul./dez. 2013 
environmental justice and, finally, the emergence of some bureaucratic mechanisms for reporting environmental crimes, we establish some of the key linkages between human rights and environmental rights in Brazil.

Keywords: enviromental rights, global meetings, human rights, United Nations.

Ao longo deste texto seguiremos dois eixos argumentativos aos quais faremos algumas referências em seu decorrer. Em primeiro lugar, trataremos os direitos humanos a partir de uma perspectiva diacrônica, concebendo-os como resultante de relações de poder forjadas em contextos históricos específicos e expressas em categorias semânticas igualmente conjunturais (Fonseca; Cardello, 2009, p. 85). Em segundo lugar, interessa o modo pelo qual a aparente estabilidade da associação entre direitos humanos e direito à vida invisibiliza as transformações da abrangência semântica do que seja a vida em questão. Isto é, trata-se de explicitar como deslocamentos na ideia de vida implicam transformações na matriz discursiva dos direitos humanos e, por conseguinte, modificam quem são os sujeitos desses direitos, quais as questões mais valorizadas e as articulações políticas que eles engendram.

Os materiais empíricos utilizados aqui serão de três ordens: matérias de jornais; relatórios, cartilhas e documentos oficiais do governo brasileiro sobre os direitos humanos ambientais; documentos relativos às conferências e aos encontros nacionais de direitos humanos, assim como os textos das reuniões globais da Organização das Nações Unidas sobre meio ambiente.

O texto está dividido em três partes, cada uma delas introduzida por uma cena que articula os direitos humanos às questões ecológicas a partir do princípio de "defesa da vida". Na primeira cena, discorremos sobre como questões relativas aos direitos reprodutivos e à proteção ambiental se fundam em um modelo de ética do futuro. Na segunda, tomamos como referência a emergência do conceito epistemológico e político de justiça ambiental para discorrer sobre uma espécie de "conversão ecológica" que perpassa o debate das questões sociais no Brasil hoje. Na terceira e última cena, nos remetemos aos processos de rotinização das vias legais de denúncia de crimes ambientais a partir das Conferências Nacionais de Direitos Humanos. Por fim, apresentamos, na conclusão, a nossa interpretação dos modos pelos quais enunciados sobre a vida da natureza e dos humanos tornam-se argumentos centrais nos debates públicos sobre o meio ambiente. 


\section{Direitos humanos e vida em três atos}

\section{Hillary Clinton e o direito à vida do feto}

Durante o mês de junho de 2012 o Brasil sediou um dos principais eventos na agenda dos organismos de governança global sobre o desenvolvimento sustentável, a Rio+20. Os números relativos ao evento permitem dimensioná-lo. Mais de uma centena de chefes de Estado estiveram presentes e, juntos, assinaram acordos e compromissos de defesa ambiental do planeta que implicarão um gasto de 513 bilhões de dólares nos próximos anos (Rio+20 em números, 2012). Duas décadas após a realização da Eco-92, a conferência de 2012 estava dirigida, sobretudo, à renovação de compromissos políticos com o desenvolvimento sustentável a partir da chamada economia verde.

Questões ecológicas, de um modo amplo, têm sido tematizadas como tópico incontornável na elaboração de políticas com capacidades variadas de abrangência ao menos desde a década de 1980 . No entanto, a não adesão de países como Estados Unidos e China em determinados acordos internacionais indicam os limites de uma hipotética aliança mundial contra a degradação ambiental. ${ }^{1} \mathrm{Na}$ conferência Rio +20 , a ausência da maioria dos presidentes e primeiros-ministros dos países que compõem o G8 foi interpretada pelos participantes do evento e pela opinião pública como um retrocesso no movimento ambiental e um sinal dos limites deste encontro específico no horizonte das políticas globais, em grande medida dependentes da adesão das grandes potências econômicas aos acordos e compromissos que seriam produzidos e assinados no evento. ${ }^{2}$ Ainda assim, esses países enviaram representantes que participaram de alguns painéis de debates e da elaboração de metas de redução de impacto ambiental.

Por ocasião da conferência, o presidente estadunidense, Barack Obama, enviou Hillary Clinton, secretária de Estado, que proferiu uma das conferências

\footnotetext{
Desde a Conferência de Estocolmo, ocorrida em 1972, a posição dos Estados Unidos em relação a acordos globais sobre o meio ambiente tem sido um parâmetro para outros países do hemisfério norte na adoção ou não de determinados compromissos ecológicos. Para um debate sobre o tema ver Acselrad (1992) e Ribeiro (2001).

2 Do grupo dos oito países que compõem o G8 apenas o chefe de Estado francês esteve presente no evento. Os outros países apenas enviaram representantes (Galvani, 2012; Justo, 2012).
} 
mais aguardadas pelo público. A cobertura midiática da manifestação de Hillary Clinton foi ampla, com grande repercussão internacional. ${ }^{3}$ Contudo, ao contrário do que se poderia imaginar em um encontro sobre a defesa do meio ambiente, o conteúdo da conferência de Hillary Clinton não versou sobre o papel dos EUA nos acordos que estavam sendo firmados, mas articulou questões ecológicas com outras relacionadas aos direitos sexuais e reprodutivos das mulheres. Afirmou a secretária: "É preciso agir sobre as claras evidências de que as mulheres são essenciais e representam a força motora do desenvolvimento sustentável. Para atingir nossas metas em desenvolvimento sustentável também temos que garantir os direitos reprodutivos da mulher. As mulheres devem poder tomar decisões sobre, se, e quando querem ter filhos." (Godoy; Lima; Mazzacaro, 2012).

O seu pronunciamento foi seguido por manifestações de representantes do Vaticano que expressaram o seu temor de que as indicações sobre os direitos sexuais e reprodutivos das mulheres enunciados no discurso de Hillary Clinton pudessem vir a ser incorporadas no documento final da Rio+20. Um temor que estava presente nas manifestações dos líderes religiosos católicos antes mesmo do pronunciamento da secretária de Estado norte-americana, visto que as questões relativas aos direitos sexuais e reprodutivos das mulheres (Na Rio+20, Vaticano..., 2012) já constavam na minuta zero 4 da conferência. A manifestação do cardeal brasileiro Dom Odilo Scherer, na Rio+20, é emblemática do empenho da Igreja Católica para que esses temas estivessem ausentes no texto final da conferência. Nesse sentido, ele afirma que não deveriam constar nos acordos que estavam sendo produzidos "uma sentença de morte imposta sobre as vidas humanas mais vulneráveis, ou seja, aquelas que estão no santuário mais seguro, que são os úteros de suas mães. [Essa sentença] não pode, sob nenhuma hipótese, ser apresentada com a nomenclatura de cuidados da saúde ou simplesmente saúde." (Na Rio+20, Vaticano..., 2012, grifo nosso).

\footnotetext{
3 O jornal britânico The Guardian (2012), por exemplo, criou uma seção em seu site exclusiva para a Rio +20 .

4 Minuta zero é a primeira versão dos textos finais de conferências e encontros. Durante tais eventos esse texto é modificado conforme as sugestões dos presentes e, ao final, apresentado em forma de carta, relatório, etc.
} 
Nesse embate entre a representante dos Estados Unidos e o alto clero da Igreja Católica, a posição eclesial parece que saiu vencedora. No texto do documento final da Conferência das Nações Unidas sobre o Desenvolvimento Sustentável, intitulado O futuro que queremos, assinado no dia 22 de junho de 2012 pelos representantes dos 188 Estados-membros, presentes na Rio +20 , não aparece qualquer referência propositiva com relação aos direitos sexuais e reprodutivos das mulheres, ainda que esse tema estivesse presente minuta zero, como vimos acima (Rio+20 termina..., 2012). Segundo a imprensa (Chagas, 2012), essa supressão foi resultado da investida de organismos ligados à Igreja Católica entre os membros das delegações presentes no evento. Assim, de modo amplo e genérico, mas significativo para o argumento que procuraremos sustentar, o texto El futuro que queremos (Naciones Unidas, 2012, p. 31) apresenta a seguinte proposição sobre saúde sexual e reprodutiva:

Pedimos que se apliquen plena y efectivamente la Plataforma de Acción de Beijing, el Programa de Acción de la Conferencia Internacional sobre la Población y el Desarrollo y los resultados de sus conferencias de examen, incluidos los compromisos relativos a la salud sexual y reproductiva y la promoción y protección de todos los derechos humanos en este contexto. Ponemos de relieve la necesidad de proporcionar acceso universal a la salud reproductiva, incluida la planificación familiar y la salud sexual, y de integrar la salud reproductiva en las estrategias y los programas nacionales.

Ainda que reconheçamos a importância dos conflitos políticos e ideológicos que os termos usados no texto do documento final do evento expressam, o intuito deste texto não nos permite analisar os posicionamentos desses global players no cenário da governança mundial, em que estão implicados não apenas Estados, mas também igrejas, movimentos sociais e grupos representativos de causas e anseios presentes na sociedade contemporânea. Assim, para manter o fio condutor do nosso argumento, a questão que formulamos é: o que os direitos sexuais e reprodutivos das mulheres têm a ver com questões ambientais? O que faz um tópico sobre saúde e planejamento familiar no documento final de uma conferência sobre desenvolvimento sustentável? Como compreender a afirmação da representante do governo dos EUA de que "as mulheres são essenciais e representam a força motora do desenvolvimento sustentável"? De que modo estão articulados as centenas de painéis sobre o clima no planeta, o desmatamento e a poluição das indústrias realizados 
durante a Rio +20 com a palestra de um arcebispo em defesa da família e contra o aborto? Enfim, de que modo, a partir de quais dispositivos e de quais jogos de forças, os enunciados relativos ao meio ambiente e à reprodução sexual se articulam com os direitos humanos?

Embora o feixe de questões apresentado seja bastante amplo, vamos seguir um eixo de reflexão que nos permite articular estes dois campos de práticas e discursos: ambiental e sexual reprodutivo. Assim, pretendemos destacar o princípio moral de defesa da vida como o ponto de interseção entre esses campos. O caráter metafísico de que se reveste, nos dois campos, esse princípio moral, por sua vez, tende a afastar tanto os atores ambientais quanto os religiosos de uma ética da responsabilidade, ainda que devamos reconhecer diferenças significativas nas concepções do que seja vida entre eles. ${ }^{5}$ Para ambos, no entanto, a luta pela vida remete à defesa da natureza como alteridade radical em relação à cultura. Desse modo, tanto para aqueles que se posicionam contrários ao aborto quanto para os denunciam a degradação do planeta pela ação predadora dos humanos que o habitam, a única conduta moral legítima seria a submissão do sujeito humano à lei natural.

$\mathrm{O}$ calcanhar de Aquiles desse posicionamento parece residir num duplo movimento de desnaturalização do humano e da desumanização da natureza que se apresenta como um oximoro. Ao remeter a natureza para um lugar utópico, conferindo-lhe um caráter sagrado, a lei natural aparece como um absoluto que se impõe desde fora da cultura humana. Nesse horizonte ético, a vida, quer na sua manifestação na forma do feto no seio materno quer na forma originária imaginada de um momento anterior ao surgimento da cultura, reveste-se de um sentido abstrato e universal. A luta pela vida apresenta-se, assim, como um compromisso com o futuro no plano individual, no caso daqueles que contrapõem-se ao aborto, e no plano planetário, no caso daqueles que denunciam a degradação das condições ambientais para as novas gerações. Ambos, portanto, engajam-se na luta, emprestando suas vozes àqueles que não têm como se pronunciar e afirmar seu próprio direito de existir. Em outras palavras, falam em nome daqueles que, mesmo ainda não tendo nascido, são a garantia da continuação da própria humanidade.

5 Para uma análise mais aprofundada sobre a relação entre direitos sexuais e reprodutivos e direitos humanos ver Steil e Toniol (2012).

Horizontes Antropológicos, Porto Alegre, ano 19, n. 40, p. 283-309, jul./dez. 2013 
A luta pela vida daqueles que ainda não são, portanto, conecta os campos da moral religiosa, que se opõe aos direitos sexuais reprodutivos das mulheres, e da ética ecológica em defesa do planeta contra o crescimento econômico não sustentável que ameaça o nosso futuro. Desse modo, para os religiosos, opor-se ao aborto não diz respeito somente a sujeitos específicos, cujas mães cogitam abortar, mas refere-se de modo muito mais amplo à própria perpetuação da humanidade que, no limite, depende da reprodução. Por outro lado, a luta dos ecologistas para salvar o planeta não se refere apenas à preservação da natureza em si, mas aponta também para a responsabilidade de cada indivíduo em garantir as condições para que a vida possa continuar a se reproduzir em suas variadas formas. O que sugerimos é que tanto na defesa da preservação da natureza como na luta pela vida dos sujeitos que ainda não nasceram o que está em jogo é aquele princípio que Hans Jonas (2005) reconhece como sendo o fundamento de uma ética do futuro.

Em seu livro $O$ princípio da responsabilidade, Jonas (2005) contrapõe à ética do presente, fundada sobre o princípio de reciprocidade, a ética do futuro, que ultrapassa os sujeitos que coexistem no agora para alcançar aqueles que ainda não existem. Em sua reflexão sobre a responsabilidade das gerações presentes para com as futuras, Jonas pretende estabelecer uma razão que fundamente o imperativo moral que estenda o laço societário àqueles que ainda não nasceram, mas que um dia serão e habitarão o planeta. Assim, a reivindicação de existência deixa de ser prerrogativa dos que já existem de fato e o direito à vida torna-se um direito também compartilhado pelos ainda-não-vivos quer no plano individual, no caso do direito do feto, quer no plano coletivo, no caso da defesa das preservação do planeta para que as gerações futuras possam existir. Assim, assumir uma responsabilidade ética para com as gerações futuras é um compromisso que deve ser tomado no presente por meio da preservação da vida na sua forma individual, de cada gestação, ou na forma planetária, que impõe o desenvolvimento sustentável como agenda política para as nações, no âmbito da governança global. Como afirma Jonas (2005, p. 91-92),

[As futuras gerações] terão o direito de nos acusar, seus antecessores, de sermos a causa de sua infelicidade, caso lhes tivermos arruinado o mundo ou a constituição humana com uma ação descuidada ou imprudente. Eles só poderiam considerar os seus progenitores diretos como responsáveis por sua existência, mas poderiam considerar os seus ancestrais distantes como responsáveis pelas condições de sua existência ou, de maneira mais geral, como os causadores iniciais

Horizontes Antropológicos, Porto Alegre, ano 19, n. 40, p. 283-309, jul./dez. 2013 
dessas condições. Portanto, para nós, contemporâneos, em decorrência do direito daqueles que virão e cuja existência podemos desde já antecipar, existe um dever como agentes causais, graças ao qual nós assumimos para com eles a responsabilidade por nossos atos cujas dimensões impliquem repercussões de longo prazo.

Para os argumentos deste texto, importa constatar a produção de um laço de relação entre presente e futuro a partir do imperativo que orienta o trecho citado, o de "que a humanidade continue existindo". O direito à vida dos humanos do futuro é, para nós, hoje, o dever de garantir uma existência digna àqueles que ainda não são e, ao mesmo tempo, o direito de trazer ao mundo sujeitos que não solicitaram sua existência, mas cujo nascimento obedece a um princípio que transcende a ética da reciprocidade, baseada no princípio basilar que impõe que façamos aos outros somente aquilo que gostaríamos que os outros nos fizessem. O limite a esse princípio é que ele deixa de fora aqueles que ainda não existem ou que estão fora da cultura humana. Assim, acreditamos que a associação entre ambiente e direitos reprodutivos que aparece na Rio+20 está assentada no fato de que ambos pautam seu discurso por uma ética do futuro, na qual está implicada de uma forma decisiva tanto a defesa da vida de humanos quanto do planeta.

\section{Direitos humanos e os mais pobres - o movimento de justica ambiental}

O ano de 1972 é considerado o marco inicial de uma agenda de encontros internacionais dirigidos ao debate sobre questões ambientais. Em julho daquele ano, ocorreu, em Estocolmo, a Conferência das Nações Unidas para o Meio Ambiente, cuja importância está menos em seus resultados concretos que se traduziram no cumprimento dos termos dos acordos oficiais assinados, e mais na emergência de uma consciência ecológica que mobilizou governos, intelectuais e organizações sociais em defesa do planeta. Embora no documento final da atividade, conhecido como Declaração de Estocolmo, haja uma série de formulações sobre a relação entre desenvolvimento e ecologia, o texto está marcado por uma ênfase na necessidade de preservação da natureza. Mais da metade dos 26 princípios deliberados na assembleia plenária final, por exemplo, estão dirigidos quase que exclusivamente à conservação dos recursos naturais, sem fazer referências a problemas sociais ou políticos. Abaixo alguns exemplos dos princípios referidos: 
Os recursos naturais da terra incluídos o ar, a água, a terra, a flora e a fauna e especialmente amostras representativas dos ecossistemas naturais devem ser preservados em benefício das gerações presentes e futuras, mediante uma cuidadosa planificação ou ordenamento. [...] Deve-se manter, e sempre que possível, restaurar ou melhorar a capacidade da terra em produzir recursos vitais renováveis. [...] Os recursos não renováveis da terra devem empregar-se de forma que se evite o perigo de seu futuro esgotamento e se assegure que toda a humanidade compartilhe dos benefícios de sua utilização. [...] Deve-se por fim à descarga de substâncias tóxicas ou de outros materiais que liberam calor, em quantidades ou concentrações tais que o meio ambiente não possa neutralizá-los, para que não se causem danos graves e irreparáveis aos ecossistemas. Deve-se apoiar a justa luta dos povos de todos os países contra a poluição. (Declaração da conferência..., 1972).

A centralidade da natureza como tema por excelência do documento não é relativizada nem mesmo quando são enunciadas questões concernentes à superação da pobreza, tal como expresso no seguinte trecho: “[...] os países em desenvolvimento devem dirigir seus esforços para o desenvolvimento, tendo presente suas prioridades e a necessidade de salvaguardar e melhorar o meio ambiente" (Declaração da conferência..., 1972). Neste sentido, a Conferência de Estocolmo se apresenta como um divisor de águas na concepção política e sociológica do desenvolvimento. Ou seja, ela acrescenta a condicionalidade ambiental ao imperativo incontornável que o desenvolvimento representava para os países pobres.

Quarenta anos depois da Conferência de Estocolmo, os eventos internacionais sobre meio ambiente já ocupam uma parte significativa nas agendas dos organismos de governança global. Reconhecer a permanência do tema nessas atividades, mesmo diante de significativas transformações políticas, econômicas e sociais nas últimas décadas, no entanto, não é o mesmo que sugerir que aquilo que seja ecologia e esteja a ela relacionada tenha permanecido inabalável nesse período.

Em 2012, a realização da Rio +20 foi celebrada como uma possibilidade de renovação dos compromissos de diferentes países em prol da defesa do meio ambiente. Contudo, logo na conferência de abertura, ao acenar com os objetivos do encontro, a presidenta do Brasil, Dilma Rousseff, deslocou a $n a-$ tureza do centro do debate ambiental e colocou em seu lugar a pobreza, a qual remete à condição humana. Em suas próprias palavras: 
A afirmação de que os seres humanos estão no centro das preocupações com o desenvolvimento sustentável colocou a erradicação da pobreza como requisito indispensável da ação politica. Esse princípio ligou de forma indissolúvel à agenda ambiental a necessidade de realizar reformas estruturais capazes de incluir as multidões de homens e mulheres e crianças que viviam e ainda vivem na pobreza e exclusão. ${ }^{6}$

Da Conferência de Estocolmo à Rio+20 há uma mudança significativa na agenda ambiental que incorpora as questões sociais no interior da questão ecológica (Declaração da conferência..., 1972). Ou seja, no cenário político e social da Rio+20, o ambiental não se interpõe apenas como uma condicionalidade ao desenvolvimento e a modernização. Mas o desenvolvimento deverá incorporar a sustentabilidade como condição para sua legitimidade. Ao mesmo tempo, o adjetivo sustentável, que se agrega ao desenvolvimento, incorpora, em seu significado e em sua prática, a erradicação da pobreza, especialmente dos grupos mais vulneráveis da sociedade, como os indígenas e as populações tradicionais. Esse sentido social, atribuído à sustentabilidade, no entanto, não resulta de um processo lógico ou natural no interior do debate oficial, travado nas sucessivas conferências da ONU sobre meio ambiente. Ao contrário, ele se impõe desde fora, como uma narrativa performática, na qual os problemas sociais são encenados nas praças e ruas da cidade do Rio de Janeiro pelos grupos indígenas e afrodescendentes que participam da Cúpula dos Povos, evento concomitante e alternativo à conferência da ONU. A emergência e visibilidade dos movimentos sociais, étnicos e de gênero nos cenários das conferências ambientais, como se pôde observar na Rio+20, vem redefinindo e alargando o conceito e o debate ecológico de modo as questões sociais, étnicas e de gênero possam ser incluídas no seu campo discursivo e enunciadas na chave da sustentabilidade.

Diante desse quadro, cabe perguntar: quais foram as transformações, sutis no plano discursivo, mas profundas do ponto de vista da ação política, que foram capazes de tornar um fórum sobre meio ambiente um dos principais espaços de debate e deliberações para o combate à pobreza no mundo? A partir de quais dispositivos de enunciação as problemáticas sociais encontraram ressonância na agenda de preservação da natureza?

6 Em vídeo disponível no YouTube (http://www.youtube.com/watch?v=b-QibvHJ5VA).

Horizontes Antropológicos, Porto Alegre, ano 19, n. 40, p. 283-309, jul./dez. 2013 
Parte da possibilidade de implicação desses dois universos discursivos - aquele que se refere à preservação da natureza e aquele relativo às problemáticas sociais - pode ser explorada a partir de uma ideia que, a partir dos anos de 1990, ganhou força nos debates públicos sobre sociedade e natureza, o conceito de justiça ambiental. Surgido na década de 1990, tal conceito refere-se à "constatação de que a crescente escassez de recursos naturais e a desestabilização dos ecossistemas afetam de modo desigual, e muitas vezes injusto, diferentes grupos sociais ou áreas geográficas" (Ioris, 2009, p. 389). Seu surgimento, enquanto categoria analítica, está intimamente relacionado à sua emergência como um dispositivo político na luta de movimento sociais diversos que têm internalizado a questão ambiental em suas pautas reivindicatórias. Nesse sentido, tornou-se uma referência recorrente na história recente dos movimentos sociais o uso da categoria conversão ambiental para expressar a luta das populações não brancas - negros, asiáticos, latinos e índios - contra as consequências negativas do desenvolvimento econômico que as atingem de forma muito mais grave e intensa do que os outros segmentos da sociedade.

$\mathrm{Na}$ origem da conversão ambiental está o movimento "o que se passa no meu quintal?" (What's in my backyard), cuja reivindicação foi a de que o governo dos Estados Unidos parasse de mandar para suas comunidades empreendimentos poluidores. Com o apoio de uma comunidade religiosa, a Comissão para Justiça Racial da Igreja de Cristo, e respaldado pelas pesquisas acadêmicas realizadas na Universidade de Atlanta, foi elaborado o relatório Toxic wastes and race in the United States: A national report on the racial and socio-economic characteristics of communities with hazardous waste sites, lançado em 1987 (United Church of Christ, 1987), que demonstrava, de forma convincente e empiricamente fundamentada, a relação direta entre danos ambientais e bairros habitados por populações não brancas. ${ }^{7}$

No Brasil, o conceito de justiça ambiental aparece, desde seu início, associado ao de ambientalização dos conflitos sociais. Nesse sentido, Leite Lopes (2004a, 2004b, 2006) e Leite Lopes et al. (2000) identificam um desses processos de ambientalização no movimento sindical, que, a partir dos anos

\footnotetext{
No site do Centro de Pesquisa em Justiça Ambiental da Universidade de Atlanta (http://www.ejrc.cau. edu/), além de diversos artigos sobre o tema, são indicadas algumas páginas na internet onde é possível comprovar os resultados de sua pesquisa. Ou seja, saber a localização e os danos ambientais a diversas populações negras que passaram a se mobilizar.
}

Horizontes Antropológicos, Porto Alegre, ano 19, n. 40, p. 283-309, jul./dez. 2013 
de 1990, passa a expressar suas demandas de classe no idioma ambiental. Essa conversão discursiva, segundo o autor, se torna plausível na medida em que a sociedade incorpora uma ética ambiental que dissemina valores ecológicos que se impõem como um habitus e uma ascese secular que engendram mudanças de comportamento das pessoas no trabalho, na vida cotidiana e no lazer. Nessa perspectiva, a incorporação deste habitus dá sentido ao conjunto de mudanças e justifica os sacrifícios que a ascese ecológica impõe aos sujeitos contemporâneos. Ou seja, ao se interpor como o ponto de conexão entre a experiência dos indivíduos e esfera social e política, o habitus opera como uma fonte de legitimidade da questão ambiental. ${ }^{8}$ É nesse contexto, que formulações sobre a defesa de uma vida humana digna - objeto da luta de diversos movimentos sociais - passa a encontrar na distribuição desigual dos custos da exploração da natureza mais uma expressão da injustiça de modelos econômicos e políticos vistos como não sustentáveis.

O desdobramento político do conceito de justiça ambiental no Brasil, entretanto, se dá especialmente pela criação da Rede Brasileira de Justiça Ambiental, que articula, como nos Estados Unidos, a ação política com pesquisas acadêmicas (Acselrad, 2004, 2010; Zhouri, 2008, Zhouri; Siano; Laschefski, 2005, Zhouri; Teixeira, 2007). Apoiada por pesquisadores, militantes e ONGs, a rede procura identificar e denunciar os casos de conflitos nos quais há uma distribuição desigual dos custos ambientais produzidos pelos grandes projetos de desenvolvimento econômico que atingem territórios e populações vulneráveis (Carvalho; Toniol, 2010). Ainda que, diferentemente dos Estados Unidos, a questão racial na Rede Brasileira não esteja no centro da mobilização social, ela não está ausente. Assim, em 2006, a Rede Brasileira realizou o I Seminário sobre Racismo Ambiental. Nesse contexto, o conceito de racismo ambiental foi formulado como segue:

Chamamos de Racismo Ambiental as injustiças sociais e ambientais que recaem de forma desproporcional sobre etnias vulnerabilizadas. O Racismo Ambiental não se configura apenas através de ações que tenham uma intenção racista, mas igualmente através de ações que tenham impacto racial, não obstante a intenção que lhes tenha dado origem. (Herculano; Pacheco, 2006, p. 20).

8 Na mesma direção, Acselrad (2004) e Zhouri e Teixeira (2007) chamam a atenção para os conflitos ambientais como indutores de novas estratégias argumentativas nos conflitos sociais.

Horizontes Antropológicos, Porto Alegre, ano 19, n. 40, p. 283-309, jul./dez. 2013 
A possibilidade de os movimentos sociais se implicarem nos agenciamentos relativos às questões ambientais e, a partir dessa implicação, produzirem articulações potentes - tal como a ideia de racismo ambiental - já estava anunciada desde a First National People of Color Environmental Leadership Summit. ${ }^{9}$ Realizada em 1991, na cidade de Washington, nos Estados Unidos, o relatório final desse encontro estabelecia alguns marcos para a produção daquilo que viriam a ser os direitos humanos ambientais. No preâmbulo desse documento consta o seguinte trecho:

NÓS, PESSOAS DE COR, reunidas nesta Primeira Cúpula Nacional de Lideranças Ambientalistas de Cor para iniciar a construção de um movimento nacional e internacional de todos os povos de cor para combater a degradação e proteger nossas terras e comunidades, restabelecendo assim nossa interdependência espiritual com a sacralidade da Mãe Terra; em respeito e celebração a cada uma de nossas culturas, linguagens e crenças sobre o mundo natural e os nossos papéis em curar a nós mesmos/as; para assegurar a justiça ambiental; para promover alternativas econômicas que possam contribuir para o desenvolvimento de meios ambientalmente seguros de subsistência; e para garantir a liberdade política, econômica e cultural que foi nos negada ao longo de mais de 500 anos de colonização e opressão, resultando no envenenamento de nossas comunidades e da terra e no genocídio de nossos povos. (Princípios..., 1991).

Há uma tensão permanente no trecho citado entre a ideia de uma cultura particular e o apelo pela defesa do meio ambiente de modo mais amplo. A evocação da "Mãe Terra" redimensiona as questões relativas à colonização e à exploração econômica de determinadas comunidades como um problema global. Desse modo, a suposta unidade ecológica, na qual se inscreve a noção da interdependência das espécies e de natureza, ${ }^{10}$ transforma as demandas sociais locais num problema de todos. ${ }^{11}$ A natureza torna-se, nesse contexto, um horizonte de agenciamento capaz de mobilizar um extenso rol de sujeitos sociais

9 Mantivemos o nome original para preservar o termo "people of color", importante para a identificação do movimento. Daqui em diante optamos pela tradução do relatório dessa conferência (Princípios..., 1991).

${ }^{10}$ É a partir de uma concepção de natureza como condição da vida humana que se pode reclamar a necessidade de um engajamento global nas causas ecológicas. Desse modo, o desaparecimento de espécies da fauna e flora passa a ser um problema para os próprios humanos.

${ }^{11}$ Essa ideia está explicitamente expressa no primeiro ponto da conferência, citada na nota 24: "1) a Justiça Ambiental afirma a sacralidade da Mãe Terra, a unidade ecológica e a interdependência entre todas a espécies, e o direito a ser livre da degradação ecológica".

Horizontes Antropológicos, Porto Alegre, ano 19, n. 40, p. 283-309, jul./dez. 2013 
e articular um leque significativo de interesses políticos, muitas vezes contraditórios. Nesse sentido, podemos observar que o movimento ambiental - com suas organizações governamentais e não governamentais, suas redes sociais e acadêmicas - apresenta-se como um poderoso agente (global player), inscrevendo na agenda da governança global não apenas as causas ecológicas, mas também transpondo demandas sociais, étnicas e de gênero, que surgem na esfera pública nacional, para a esfera global.

Ainda sobre o relatório resultante da reunião de cúpula em Washington, entre os 17 princípios listados como centrais para a justiça ambiental chama a nossa atenção, para os fins aqui propostos, um deles:

A Justiça Ambiental considera atos governamentais de injustiça ambiental uma violação de lei internacional: da Declaração Universal de Direitos Humanos e da Convenção para a Prevenção e Repressão do Crime de Genocídio das Nações Unidas. (Princípios..., 1991).

Este parece ser um dos primeiros registros de associação explícita entre direitos humanos e a problemática ambiental. A estratégia dos movimentos sociais de enunciarem suas demandas a partir de uma articulação com causas que se apresentam como universais, parece, nesse ponto, ser reiterada a partir da evocação de, pelo menos, três outros modos globais de agenciamento: a ideia de uma lei internacional, a Declaração Universal de Direitos Humanos, e a Convenção para a Prevenção e Repressão do Crime de Genocídio das Nações Unidas. O que gostaríamos de sugerir é que a associação entre a questão ambiental e os direitos humanos está assentada na potencialidade de agenciamento de discursos que remetem ao contexto da governança global.

Tal associação, no entanto, não se constituiu apenas como elemento de visibilidade para grupos e demandas sociais já formuladas. ${ }^{12}$ Sua produção veio acompanhada da emergência de determinadas expertises, políticas, tecnologias e sujeitos sociais. Exemplo emblemático desse processo é o Movimento dos Atingidos por Barragens (MAB). Fundado no início da década de 1990,

12 Tampouco para esses grupos, que, a partir da incorporação de questões ecológicas, dão visibilidade à sua própria agenda política, se trata apenas de um cálculo estratégico. A entrada em discursividades ecológicas não deixa imunes os posicionamentos desses sujeitos e grupos.

Horizontes Antropológicos, Porto Alegre, ano 19, n. 40, p. 283-309, jul./dez. 2013 
o MAB foi formado no bojo dos movimentos de luta pela terra a partir do reconhecimento de um grande contingente de famílias que haviam perdido seus locais de trabalho e moradia por conta da construção de barragens no interior do Brasil. A rede de sujeitos e grupos que se articula a partir do MAB é apresentada no site do movimento a partir de suas ações de sensibilização da sociedade civil sobre a questão das barragens e das negociações que cada um desses atores trava com o governo em diferentes esferas. ${ }^{13}$

Assim, no material divulgado nas sessões "notícias" e "glossário", os discursos ambiental e dos direitos humanos são acionados com frequência. Tomando como referência apenas as últimas 20 notícias, divulgadas no site, ${ }^{14}$ encontramos, pelo menos, cinco matérias que articulam as demandas do MAB com questões ambientais e dos direitos humanos. As manchetes dessas notícias indicam parte de seus teores: "Criada a Comissão Estadual da Verdade no RS” (Barbosa, 2012), "Atingidos por barragens inauguram unidade de produção agroecológica", "MAB debate participação das mulheres no Vale do Ribeira", "MAB discute uso da água do lago da barragem de Barra Grande", "Movimento Popular Urbano celebra dia da Mulher Negra, Sul Americana e Caribenha" (Movimento dos Atingidos por Barragens, 2012a, 2012b, 2012c, 2012d). Enfim, a produção de enunciados, relacionados a esses campos discursivos a que vimos nos referindo, não somente redefine práticas, valores e significados, mas também empodera e potencializa os sujeitos para agir no contexto global. Ainda, em relação às categorias, destacadas no glossário do $\mathrm{MAB}$, observamos a referência frequente à natureza e à vida, a partir de definições que remetem ao paradigma científico da biologia e da geografia. ${ }^{15}$

13 Ver http://www.mabnacional.org.br/.

14 Essas notícias compreendem os dias 20 de julho a 2 de agosto de 2012.

15 Tal como no site, reproduzimos as palavras reunidas no glossário (http://www.mabnacional.org.br/ glossario) transcrevendo os termos da segunda categoria em itálico: Afluente; Aquífero; Área degradada; Arrendatário; Assoreamento; Atingido e atingida por barragem; Bacia hidrográfica; Barragem; Biota; Conselho Nacional do Meio Ambiente (CONAMA); Cota; Enchimento; Escada de peixe; Estudo de Impacto Ambiental (EIA); Estudos de Inventário Hidrelétrico; Estudos de Viabilidade; Floresta aluvial; Fluvial; Jusante; Lençol freático; Licença de instalação; Licença de operação; Licença Prévia; Manancial; Medidas compensatórias; Medidas mitigadoras; Montante; Palafita; Potência; Relatório de Impacto Ambiental (RIMA); Remanso; Sistema Nacional do Meio Ambiente (SISNAMA); Usina hidrelétrica (UHE); Vazão; Vertedouro. 


\section{A. institucionalização dos direitos humanos como direito à vida}

Durante a Rio+20 não foram poucas as atividades dirigidas ao debate do Terceiro Plano Nacional de Direitos Humanos (PNDH-3), lançado em 2010 (Brasil, 2010). Em que pesem as inúmeras críticas que ambientalistas e representantes da sociedade civil fizeram ao PNDH-3, para os movimentos ambientais ele representou um avanço significativo, uma vez que instituiu determinadas rotinas burocráticas no âmbito do Estado brasileiro para a realização de denúncias de crimes ambientais. Assim, torna-se relevante explorar o modo pelo qual a temática ambiental foi incorporada como tópico a ser discutido nas conferências nacionais de direitos humanos, voltadas para a formulação dos PNDH.

Convocadas com a finalidade precípua de recolher e sistematizar as propostas e demandas da sociedade civil para a elaboração dos Programas Nacionais de Direitos Humanos em suas três versões: PNDH-1 (Brasil, 1996), PNDH-2 (Brasil, 2002) e PNDH-3 (Brasil, 2010), as conferências nacionais se constituíram, em suas 11 edições, até 2008, no principal instrumento de diálogo do governo com a sociedade civil sobre os Direitos Humanos no Brasil. Nessa trajetória, vamos observar a diversificação das parcerias que a Secretaria Especial de Direitos Humanos, enquanto entidade promotora, estabelece com os demais atores do próprio Estado e da sociedade civil. O último evento, por exemplo, foi organizado de forma tripartite pela Secretaria Especial de Direitos Humanos da Presidência da República, pela Comissão de Direitos Humanos e Minorias da Câmara dos Deputados e pelo Fórum de Entidades Nacionais de Direitos Humanos, manifestando um enquadramento dos direitos humanos numa visão que se organiza sobre três pilares: governo, congresso nacional e sociedade civil.

Diversificam-se também as entidades convocadas para as conferências, apontando para uma presença cada vez mais intensa das ONGs, ao mesmo tempo em que a representação dos movimentos sociais se faz por meio de fóruns que congregam conjuntos de organizações, articuladas em torno de subtemas dos direitos humanos. As conferências se tornam, assim, o canal privilegiado pelo qual as demandas das crianças e adolescentes, das mulheres, dos homossexuais, dos índios e dos afrodescendentes, assim como do próprio planeta, chegam ao Estado e são incorporadas como políticas públicas. Esses 
subtemas, ao serem relacionados com questões sociais e político-ideológicas, alargam o campo semântico dos direitos humanos e diversificam as demandas, temas, questões e propostas que integram o conteúdo dos Programas Nacionais de Direitos Humanos. Estes, por sua vez, tornam-se um instrumento de legitimação para o governo democrático, de indexação de valor às demandas que se expressam no seu texto e de reconhecimento para os órgãos do Estado e as organizações da sociedade civil que participam das conferências.

Vale destacar, nos documentos relativos a esses eventos, a constante manifestação de políticos, membros de ONGs e da sociedade civil, chamando a atenção para questões ambientais. Na II Conferência, em 1997, por exemplo, foi dada grande centralidade à fala de um cacique Xavante que versou sobre o desmatamento de sua reserva. Assim como, na III (1998), IV (1999), VII (2002) e VIII (2003) conferências, as definições de direitos humanos, formuladas nesse campo discursivo, passam a incluir o ambiente como sujeito de direitos. Essa inclusão, por sua vez, frequentemente é respaldada por formulações de conferências globais sobre os direitos humanos, como a conferência da ONU, realizada em Viena, em 1992, que classifica as questões ambientais como direitos humanos de terceira geração.

Enquanto o registro da primeira geração de direitos políticos, civis e cívicos se consolida balizando o poder de ação do Estado, toma corpo a segunda geração dos direitos sociais, econômicos e culturais, impondo uma ação positiva ao Estado, e uma terceira geração de direitos, desta vez coletivos, emerge: direito à infância, direito ao meio ambiente, direito à cidadania, direito ao desenvolvimento dos povos, enfim reconhecidos na Conferência de Viena, em 1993. (Brasil, 2002, grifo no original).

Já em 2008, na XI Conferência Nacional de Direitos Humanos, o primeiro eixo temático de discussão proposto foi, justamente, "os impactos socioambientais do atual modelo de desenvolvimento nacional e as violações de direitos provocadas por grandes obras de infraestrutura e pelo agronegócio". Parte dessa centralidade decorre da preparação, naquele período, do III Programa Nacional de Direitos Humanos (PNDH-3), que daria significativa relevância para a questão ambiental. Assim, das 25 diretrizes de ação que reúnem os objetivos estratégicos e ações programáticas do programa, duas delas versam sobre a questão ambiental. Em sua formulação, estabelecem como 
diretrizes governamentais: 1) promover e proteger os direitos ambientais como direitos humanos, incluindo as gerações futuras como sujeitos de direitos; 2) implementar o modelo de desenvolvimento sustentável, com inclusão social e econômica, ambientalmente equilibrado e tecnologicamente responsável, cultural e regionalmente diverso, participativo e não discriminatório (Brasil, 2010).

A primeira diretriz, destacada acima, explicita uma das implicações centrais da articulação entre direitos ambientais e direitos humanos que discutimos na primeira parte deste texto: o princípio da responsabilidade moral para com as gerações futuras por meio da ampliação temporal do direito à vida. Como apresentamos noutro texto (Steil; Toniol, 2012), nas décadas de $1970 \mathrm{e}$ 1980, a ideia de direitos humanos, no Brasil, esteve bastante associada à luta pelos direitos políticos de presos políticos da ditadura militar e os direitos sociais dos pobres. Os direitos humanos, nesse momento, estavam associados a demandas imediatas e urgentes que emergiam num contexto repressivo: garantir a vida de presos políticos, que eram torturados pelo regime militar, e a sobrevivência das populações empobrecidas, relegadas à condição de marginalidade imposta pelo modelo de desenvolvimento econômico adotado.

A partir dos anos de 1990, com a redemocratização do país, o discurso sobre os direitos humanos passam a incorporar os direitos sexuais e reprodutivos como um novo campo de disputas, redefinindo as posições dos principais contendores e aliados na arena política social. Já não se trata de uma disputa da Igreja Católica, representada pelas pastorais sociais e a Teologia da Libertação, e os movimentos sociais de esquerda contra o Estado autoritário e repressor, mas da mesma Igreja Católica, representada pelos grupos conservadores que conquistam a hegemonia institucional dentro dela, aliada com as igrejas evangélicas, contra o movimento feminista e as ONGs, que buscam inscrever suas demandas relativas aos direitos sexuais e ao gênero na agenda da definição das políticas públicas. Em alguma medida, poderíamos dizer que a disputa já não é contra o Estado, mas no seu interior, pelo seu controle ideológico, uma vez que, ao se democratizar, ele também se pluraliza. Nesse cenário político, as questões relativas ao aborto e o reconhecimento institucional da união entre pessoas do mesmo sexo emergem como disputas centrais no campo discursivo dos direitos humanos, que são encenadas no momento dos pleitos políticos, como mostramos no texto anterior da última eleição para presidente no Brasil (Steil; Toniol, 2012) ou por ocasião de eventos de grande

Horizontes Antropológicos, Porto Alegre, ano 19, n. 40, p. 283-309, jul./dez. 2013 
repercussão internacional, como é o caso da conferência Rio+20, que estamos analisando neste texto.

A segunda diretriz, que estacamos no PNDH-3, refere-se às contradições que emergem na gestão pública entre os objetivos estratégicos e às ações programáticas, voltadas para o desenvolvimento social e o crescimento econômico, e os custos ambientais que estão necessariamente implicados no desenvolvimento. Aqui também se estabelece um campo de disputas, no qual os seus principais protagonistas são, de um lado, os ambientalistas, e, de outro, os ruralistas, cada qual com seus aliados circunstanciais. Mas se as disputas em torno dos direitos sexuais e reprodutivos tem como palco privilegiado as eleições e os eventos, as dos ruralistas e ambientalistas são travadas especialmente no Congresso Nacional, como pudemos ver recentemente na luta acirrada pela aprovação do Código Florestal no Brasil. ${ }^{16}$ Enfim, a análise do PNDH-3, ao mesmo tempo em que revela a pluralidade ideológica presente no Estado democrático brasileiro, também mostra que a questão ambiental se inscreve no âmbito do Estado como um direito inalienável de humanos e não humanos, das gerações presentes e futuras, daqueles que já existem e dos que serão chamados à vida. Sua inscrição, no entanto, traz as marcas das contradições presentes na sociedade, de forma que seu enunciado vem sempre associado com a necessidade premente do desenvolvimento para a superação da pobreza e o crescimento econômico. Estas contradições podem ser observadas nas proposições expressas nos eixos temáticos do Programa Nacional dos Direitos Humanos: 1) avançar na implantação da reforma agrária, como forma de inclusão social e acesso aos direitos básicos, de forma articulada com as políticas de saúde, educação, meio ambiente e fomento à produção alimentar; 2) integrar políticas sociais e de geração de emprego e renda para o combate à pobreza urbana, em especial de catadores de materiais recicláveis e população em situação de rua; 3 ) incluir o tema dos direitos humanos nos instrumentos e relatórios dos órgãos ambientais; 4) assegurar a proteção dos

\footnotetext{
16 Ao longo dos anos de 2011 e de 2012 o Congresso Nacional e o Senado brasileiro estiveram mobilizados com o debate, junto a setores da sociedade civil, sobre o novo Código Florestal do país. Ruralistas e ambientalistas polarizaram a disputa em torno de algumas regulações que implicariam, por exemplo, a possibilidade de maior ou menor desmatamento para a produção agrícola. Depois de aprovado pelos senadores e deputados, o texto foi encaminhado para a aprovação da presidenta Dilma Rousseff. Em outubro de 2012, para o contragosto de ruralistas, o Código Florestal foi sancionado com nove vetos presidenciais que atendem, em parte, reivindicações dos movimentos ambientais.
}

Horizontes Antropológicos, Porto Alegre, ano 19, n. 40, p. 283-309, jul./dez. 2013 
direitos ambientais e dos direitos humanos no Código Florestal; 5) incluir, nos programas educativos, o direito ao meio ambiente como direito humano.

Deste rol de compromissos assumidos pelo Estado como horizonte de suas ações estratégicas e políticas públicas, gostaríamos de assinalar dois aspectos que nos parecem importantes para o argumento que vimos desenvolvendo. O primeiro é a continuidade do tema concernente ao combate à pobreza, articulado com soluções que envolvem a ética ambiental, possível de ser localizado desde as primeiras formulações dos direitos humanos no âmbito do estado democrático brasileiro. O segundo é a criação de dispositivos burocráticos e legais na rotina do Estado para tornar efetiva a articulação entre direitos ambientais e direitos humanos. Sobre este segundo aspecto vamos discorrer na conclusão deste texto.

\section{Conclusão}

No dia 7 de abril de 2010 os relatores dos Direitos Humanos ao Meio Ambiente da Plataforma Brasileira de Direitos Humanos, Econômicos, Sociais, Culturais e Ambientais (Plataforma Dhesca) ${ }^{17}$ lançaram, em Brasília, o relatório Missão Xingu: violações de direitos humanos e impactos socioambientais e no licenciamento da usina hidrelétrica de Belo Monte. O documento foi apresentado por ocasião da reunião da Comissão de Direitos Humanos da Câmara dos Deputados e contou com a presença de ministros de Estado, de representantes da Procuradoria da República e de membros do Movimento de Atingidos por Barragens (Relatório..., 2010). Esse ato teve ampla cobertura jornalística, sobretudo, porque, seis dias antes, a Comissão Ibero-americana de Direitos Humanos (CIDH) havia encaminhado uma medida cautelar ao

17 Em seu site, a Plataforma Dhesca é descrita como "uma articulação nacional de 36 movimentos e organizações da sociedade civil que desenvolve ações de promoção, defesa e reparação dos Direitos Humanos Econômicos, Sociais, Culturais e Ambientais (doravante abreviados em Dhesca), visando o fortalecimento da cidadania e a radicalização da democracia. Seu objetivo geral é contribuir para a construção e fortalecimento de uma cultura de direitos, desenvolvendo estratégias de exigibilidade e justiciabilidade dos Dhesca, bem como incidindo na formulação, efetivação e controle de políticas públicas sociais. A Dhesca Brasil atua em três frentes de trabalho: o Monitoramento em Direitos Humanos no Brasil; a Integração Regional e as Relatorias de Direitos Humanos." (Plataforma Brasileira de Direitos Humanos Econômicos, Sociais, Culturais e Ambientais, 2012b).

Horizontes Antropológicos, Porto Alegre, ano 19, n. 40, p. 283-309, jul./dez. 2013 
governo brasileiro, requerendo a suspensão da construção da usina hidrelétrica de Belo Monte, alegando violação dos direitos humanos.

A Plataforma Dhesca apresenta-se no contexto das disputas ambientais como um importante ator social na consolidação, entre os principais grupos de defesa dos direitos humanos, dos direitos ambientais como um direito à vida. No ano 2000, essa plataforma foi criada a partir da reunião do Movimento Nacional de Direitos Humanos (MNDH), da Rede de Articulação e Ação pelo Direito Humano a se Alimentar (Fian Brasil), do Centro de Justiça Global (CJG), do Gabinete de Assessoria Jurídica às Organizações Populares (Gajop), da Comissão de Justiça e Paz de São Paulo (CJP-SP) e da Federação dos Órgãos para Assistência Social e Educacional (Fase) (Plataforma Brasileira de Direitos Humanos Econômicos, Sociais, Culturais e Ambientais, 2012a). Nenhum desses grupos tem a problemática ambiental como a sua principal bandeira política, contudo, desde o início da primeira década do século XXI, a maior parte deles passou a assinalar a possibilidade de associação entre suas demandas específicas e as questões ambientais.

Em 2008 a Plataforma Dhesca produziu a cartilha Direito humano ao meio ambiente (Lisboa; Barros, 2008) que, posteriormente, foi adotada pela Secretaria Especial dos Direitos Humanos (SEDH) como recurso didático para o sistema nacional de ensino. Além de uma extensa narrativa sobre a trajetória de leis brasileiras direcionadas à proteção da natureza, essa cartilha apresenta, em seu último tópico, a sistematização dos caminhos burocráticos necessários para o encaminhamento de uma denúncia de violação dos direitos humanos ambientais. Neste percurso burocrático, que diz bastante sobre como a associação dessas matrizes discursivas se institucionalizaram, estão citados: Ministério Público Federal, SEDH, Ministério do Meio Ambiente, Funai, Comissão Nacional de Desenvolvimento Sustentável dos Povos e Comunidades Tradicionais, entre outros. Tais órgãos, assim como os outros listados, deixam claro que, a partir da correlação de forças produzida no contexto da emergência dos direitos humanos ambientais, os coletivos indígenas se fortaleceram enquanto atores políticos. Esse fato não é mera decorrência de que esses sujeitos são, normalmente, os mais afetados pelas obras de grande impacto ambiental, mas está associado às transformações que vimos assinalando ao logo deste texto no campo discursivo dos direitos humanos. 
No relatório Missão Xingu, citado acima, os crimes contra os Direitos Humanos relacionados com a construção da usina hidrelétrica de Belo Monte não dizem respeito somente às populações indígenas da região, mas referem-se também à floresta amazônica. Sustentando a ideia de que a existência humana está intimamente relacionada com a preservação do ambiente, esse relatório parece indicar que a persistência da afirmação de que o mais importante é assegurar o direito à vida não significa que seguimos falando dos mesmos sujeitos e direitos. Agora, a vida referida na chave dos direitos humanos já não é tão somente a vida da humanidade, mas também a vida da natureza.

\section{Referências}

ACSELRAD, H. (Org.). Meio ambiente e democracia. Rio de Janeiro: Ibase, 1992.

ACSELRAD, H. Justiça ambiental - ação coletiva e estratégias argumentativas. In: ACSELRAD, H. HERCULANO, S.; PADUA, J. (Org.). Justiça ambiental e cidadania. Rio de Janeiro: Relume Damará: Fundação Ford, 2004. p. 23-40.

ACSELRAD. H. 2010. Ambientalização das lutas sociais. Revista Estudos Avançados, v. 24, n. 68, p. 103-119, 2010.

BARBOSA, V. Criada a Comissão Estadual da Verdade no RS. Movimento dos Atingidos por Barragens, 20 jul. 2012. Disponível em: $<\mathrm{http}: / / \mathrm{www}$. mabnacional.org.br/noticia/criada-comiss-estadual-da-verdade-no-rs $>$. Acesso em: 2 ago. 2012.

BRASIL. Câmara dos Deputados. Comissão de Direitos Humanos. VII Conferência Nacional de Direitos Humanos. Brasília, 2002. Disponível em: $\quad<$ www.camara.gov.br/Internet/comissao/index/perm/cdh/ultimos informes/28052002 - Relatorio previo da VII Conferência Nacional de Direitos Humanos.htm>. Acesso em: 1 ago. 2012.

BRASIL. Ministério da Justiça. Programa Nacional de Direitos Humanos. Brasília, 1996. Disponível em: <http://www.dhnet.org.br/dados/pp/pndh/ textointegral.html>. Acesso em: 1 ago. 2012. 
BRASIL. Ministério da Justiça. Secretaria de Estado dos Direitos Humanos. Programa Nacional de Direitos Humanos - PNDH II. Brasília, 2002. Disponível em: $<$ http://www.dhnet.org.br/dados/pp/edh/pndh_2_integral. pdf $>$. Acesso em: 1 ago. 2012.

BRASIL. Secretaria de Direitos Humanos da Presidência da República. Programa Nacional de Direitos Humanos (PNDH-3). Brasília, 2010. Disponível em: <http://portal.mj.gov.br/sedh/pndh3/pndh3.pdf >. Acesso em: 1 ago. 2012.

CARVALHO, I. C. de M.; TONIOL, R. Ambientalização, cultura e educação: diálogos, traduções e inteligibilidades possíveis desde um estudo antropológico da educação ambiental. Revista Eletrônica do Mestrado em Educação Ambiental, v. esp., p. 1-12, 2010.

CHAGAS, A.. Marta Suplicy: com pressão religiosa, Rio+20 é derrota para mulher. Terra, 20 jun. 2012. Disponível em: <http://invertia.terra.com.br/ sustentabilidade/rio20/noticias/0,,OI5849202-EI20323,00-Marta+Suplicy+ com + pressao + religiosa + Rio + e + derrota + para + mulher.html $>$. Acesso em: 27 jul. 2012.

DECLARAÇÃO DA CONFERÊNCIA das Nações Unidas sobre o Meio Ambiente Humano - 1972. Documento também conhecido como Declaração de Estocolmo. Tradução não oficial. Organização das Nações Unidas, 1972. Disponível em: <http://www.onu.org.br/rio20/img/2012/01/estocolmo1972. pdf $>$. Acesso em: 15 out. 2012.

FONSECA, C.; CARDARELlO, A. Direitos dos mais e menos humanos. Horizontes Antropológicos, Porto Alegre, v. 5, n. 10, 1999.

GALVANI, M. D. Chefes de Estado são recebidos na Rio+20 com 30 conselhos da sociedade civil. UOL Notícias, 20 jun. 2012. Disponível em: $<$ http:// noticias.uol.com.br/meio-ambiente/ultimas-noticias/redacao/2012/06/20/ chefes-de-estado-sao-recebidos-na-rio20-com-30-conselhos-da-sociedadecivil.htm>. Acesso em: 1 ago. 2012. 
GODOY, F.; LIMA, M.; MAZZACARO, N. Hillary Clinton defende 'direito reprodutivo' das mulheres em discurso na Rio+20. O Globo, 22 jun. 2012. Disponível em: <http://oglobo.globo.com/rio20/hillary-clinton-defendedireito-reprodutivo-das-mulheres-em-discurso-na-rio20-5285787>. Acesso em: 27 jul. 2012.

HERCULANO, S.; PACHECO, T. (Org.). Racismo ambiental: I Seminário Brasileiro contra o Racismo Ambiental. Rio de Janeiro: Fase, 2006.

IORIS, A. A. R. O que é justiça ambiental. Ambiente e Sociedade, v. 12, n. 2, p. 389-392, 2009.

JONAS, H. O princípio da responsabilidade. Rio de Janeiro: Contraponto; PUC-Rio, 2005.

JUSTO, M. Rio+20: “A atual cúpula já não é um projeto do G8”. Carta Maior, 13 jun. 2012. Disponível em: <http://www.cartamaior.com.br/templates/ materiaMostrar.cfm?materia_id=20328>. Acesso em: 1 ago. 2012.

LEITE LOPES, J. S. (Org.). A ambientalização dos conflitos sociais: participação e controle público da poluição industrial. Rio de Janeiro: RelumeDumará, 2004a.

LEITE LOPES, J. S. Participação pública e controle da poluição: a ambientalização dos conflitos sociais. Revista de Ciências Sociais, Fortaleza, v. 35, n. 1 , p. $20-30,2004$ b.

LEITE LOPES, J. S. Sobre processos de ambientalização dos conflitos e sobre dilemas da participação. Horizontes Antropológicos, v. 12, p. 31-64, 2006.

LEITE LOPES, J. S. et al. Naturalização e estranhamento: alguns aspectos da construção social da poluição ambiental em Itaguaí, Angra dos Reis e Volta Redonda, RJ. Cadernos do Ippur, Rio de Janeiro, v. 1, p. 181-196, 2000.

LISBOA, M.; BARROS, J. N. Direito humano ao meio ambiente. Curitiba: Plataforma Dhesca Brasil, 2008. Disponível em: <http:// www.dhescbrasil.org.br/index.php?option $=$ com_docman\&task $=$ doc download\&gid=3\&Itemid=197>. Acesso em: 2 ago. 2012. 
MOVIMENTO DOS ATINGIDOS POR BARRAGENS. Atingidos por barragens inauguram unidade de produção agroecológica. 24 jul. 2012a. Disponível em: $\quad<\mathrm{http}$ //www.mabnacional.org.br/noticia/atingidos-porbarragens-inauguram-unidade-produ-agroecol-gica $>$. Acesso em: 2 ago. 2012.

MOVIMENTO DOS ATINGIDOS POR BARRAGENS. MAB debate participação das mulheres no Vale do Ribeira. 2 ago. 2012b. Disponível em: $<$ http://www.mabnacional.org.br/noticia/mab-debate-participa-das-mulheresno-vale-do-ribeira $>$. Acesso em: 2 ago. 2012

MOVIMENTO DOS ATINGIDOS POR BARRAGENS. MAB discute uso da água do lago da barragem de Barra Grande. 24 jul. 2012c. Disponível em: $<$ http://www.mabnacional.org.br/noticia/mab-discute-uso-da-gua-do-lagoda-barragem-barra-grande>. Acesso em: 2 ago. 2012.

MOVIMENTO DOS ATINGIDOS POR BARRAGENS. MPU celebra dia da Mulher Negra, Sul Americana e Caribenha. 25 jul. 2012d. Disponível em: $<$ http://www.mabnacional.org.br/noticia/mpu-celebra-dia-da-mulher-negrasul-americana-e-caribenha>. Acesso em: 2 ago. 2012.

NACIONES UNIDAS. Asamblea General. El futuro que queremos. 24 jul. 2012. Disponível em: <http://daccess-dds-ny.un.org/doc/UNDOC/LTD/ N12/436/91/PDF/N1243691.pdf>. Acesso em: 27 jul. 2012.

NA RIO+20, VATICANO critica "ameaça à família", sem mencionar aborto nem "direitos reprodutivos". UOL Notícias, 22 jun. 2012. Disponível em: $<$ http://noticias.uol.com.br/cotidiano/ultimas-noticias/2012/06/22/na-rio20vaticano-critica-ameaca-a-familia-humana-sem-mencionar-aborto-e-semtocar-no-termo-direitos-reprodutivos.htm>. Acesso em: 27 jul. 2012.

PLATAFORMA BRASILEIRADE DIREITOS HUMANOS ECONÔMICOS, SOCIAIS, CULTURAIS E AMBIENTAIS. Históricos. 2012a. Disponível em: $<$ http://www.dhescbrasil.org.br/index.php?option=com_content\&view= article \&id=109\&Itemid=106>. Acesso em: 21 out. 2012. 
PLATAFORMA BRASILEIRA DE DIREITOS HUMANOS ECONÔMICOS, SOCIAIS, CULTURAIS E AMBIENTAIS. Quem somos. 2012b. Disponível em: $<$ http://www.dhescbrasil.org.br/index.php?option=com_content\&view=c ategory\&layout $=$ blog $\& \mathrm{id}=46 \&$ Itemid $=108>$. Acesso em: 21 out. 2012.

PRINCÍPIOS de justiça ambiental. Tradução de Sabrina Lopes. 1991. Disponível em: <http://www.justicaambiental.org.br/projetos/clientes/noar/ noar/UserFiles/17/File/17_principios.pdf $>$. Acesso em: 1 ago. 2012.

RELATÓRIO denuncia violações de direitos humanos no licenciamento da Usina de Belo Monte (PA). Portal do Meio Ambiente, 6 abr. 2010. Disponível em: $\quad<$ http://portaldomeioambiente.org.br/editorias-editorias/energia/ belo-monte/3743-relatorio-denuncia-violacoes-de-direitos-humanos-nolicenciamento-da-usina-de-belo-monte-pa>. Acesso em: 2 ago. 2012.

RIBEIRO, W. C. A ordem ambiental internacional. São Paulo: Contexto, 2001.

RIO+20 EM NÚMEROS. Rio+20, 2012. Disponível em: <http://www.rio20. info/2012/noticias-2/rio20-em-numeros $>$. Acesso em: 28 jul. 2012.

RIO+20 TERMINA e documento final 'O Futuro que Queremos' é aprovado com elogios e reservas. ONUBR, 22 jun. 2012. Disponível em: $<$ http://www. onu.org.br/rio20-termina-e-documento-final-o-futuro-que-queremos-eaprovado-com-elogios-e-reservas $>$. Acesso em: 28 jul. 2012.

STEIL, C. A.; TONIOL, R. 2012. Direitos humanos e igreja católica no contexto das eleições para presidência do Brasil em 2010. In: AMEIGEIRAS, A. R. (Org.). Cruces, intersecciones, conflictos: relaciones político religiosas en Latinoamérica. Buenos Aires: CLACSO, 2012. p. 79-108.

THE GUARDIAN. Environment. Rio+20 Earth Summit. 2012. Seção dedicada à conferência na versão online do jornal. Disponível em: $<$ http:// www.guardian.co.uk/environment/rio-20-earth-summit>. Acesso em: 27 jul. 2012. 
UNITED CHURCH OF CHRIST. Commission for Racial Justice. Toxic wastes and race in the United States: A national report on the racial and socioeconomic characteristics of communities with hazardous waste sites. New York: Public, 1987.

ZHOURI, A. Justiça ambiental, diversidade cultural e accountability: desafios para a governança ambiental. Revista Brasileira de Ciências Sociais, v. 23, p. 97-107, 2008.

ZHOURI, A.; TEIXEIRA, R. O. S. Desenvolvimento, conflitos sociais e violência no Brasil rural: o caso das hidrelétricas. Ambiente e Sociedade, Campinas, v. 10, p. 19-45, 2007.

ZHOURI, A.; SIANO, D. B. P.; LASCHEFSKI, K. (Org.). A insustentável leveza da política ambiental: desenvolvimento e conflitos socioambientais. Belo Horizonte: Autêntica, 2007.

Recebido em: 10/12/2012

Aprovado em: 04/06/2013 